\title{
Culpar a vítima ainda é o modus operandi da linguagem jornalística? Análise dos títulos no webjornalismo do portal G1 sobre o estupro (quadriênio 2016-2019)
}

\author{
Rakell Dhamarys Moreira' \\ Angelita Pereira de Lima² \\ Luciano Rodrigues Castro 3 \\ Ana Paula de Castro Neves ${ }^{4}$
}

\begin{abstract}
Resumo
Este artigo adota a análise de discurso crítica (ADC) como caminho para analisar os títulos de webjornalismo no período de 2016 a 2019, veiculadas no G1, uma das maiores plataformas de jornalismo digital no Brasil, para verificar como os discursos midiáticos persistem nas práticas narrativas que culpabilizam as mulheres vítimas de estupro. A despeito dos progressos alcançados no ordenamento jurídico e nas políticas públicas de combate à violência, no campo da linguagem as mulheres vítimas de estupro, continuam sendo culpabilizadas. Os dados coletados indicam que os títulos das notícias digitais, no período de 2016 a 2019, utilizam expressões linguísticas que atribuem à mulher a culpa pela violência sofrida, o que contribui para a reprodução e manutenção da violência de gênero.
\end{abstract}

\section{Palavras-Chave}

Webjornalismo. Análise de Discurso Crítica. Estupro.

\begin{abstract}
This article adopts critical discourse analysis (ADC) as a way to analyze webjournalism titles from 2016 to 2019, published in G1, one of the largest digital journalism platforms in Brazil, to verify how media discourses persist in narrative practices. that blame women victims of rape. Despite the progress made in the legal system and public policies to combat violence, women victims of rape continue to be blamed in the language field. The data collected indicate that the headlines of digital news, from 2016 to 2019, use language expressions that blame women for the violence suffered, which contributes to the reproduction and maintenance of gender violence.
\end{abstract}

\section{Palavras-Chave:}

Web journalism. Critical Discourse Analysis. Rape.

1 Mestranda em Direitos Humanos pela Universidade Federal de Goiás. adv.rakelldhamarys@gmail.com

2 Doutora em Geografia pela Universidade Federal de Goiás. angelitalimaufg@gmail.com

3 Mestrando em Direitos Humanos do Programa de Programa de Pós-Graduação Interdisciplinar em Direitos Humanos - (PPGIDH) da Universidade Federal de Goiás. ro.luciano88@gmail.com

4 Mestranda em Direitos Humanos do Programa de Programa de Pós-Graduação Interdisciplinar em Direitos Humanos - (PPGIDH) da Universidade Federal de Goiás. apcastro_1@hotmail.com 


\section{VOZES $_{\text {\&IÁLORO }}^{\mid}$}

Itajaí, v. 18, n. 02, jul/dez 2019

\section{Introdução}

Este trabalho resulta das experiências de pesquisa e extensão no grupo Benedita Tatu, coordenado pela professora doutora Angelita Pereira Lima no âmbito da Faculdade de Informação e Comunicação da Universidade Federal de Goiás. Sua concepção gira em torno de textos webjornalísticos que procuram narrar ocorrências de estupro no portal G1, no quadriênio 2016 a 2019.

A amostra utilizada não representa um hall taxativo e tampouco procura-se aferir conclusões gerais a partir deste estudo. Antes, procuramos oferecer os resultados aqui apresentados como percepções em processo de desenvolvimento ligadas às pesquisas desenvolvidas no citado grupo de pesquisa.

Parte-se do pressuposto de que as narrativas das matérias selecionadas respeito de violência de gênero contra a mulher em jornais online brasileiros apresentam uma propensão de estrutura textual com foco na vítima e, raramente, no agressor. Portanto, no presente artigo analisam-se quatro narrativas de mulheres vítimas de estupros, publicados no portal de notícias online G1, cada uma correspondendo a um ano do quadriênio 20162019, com o objetivo de demonstrar como essa focalização contribui para culpabilizar as mulheres vítimas de violência sexual.

Este estudo lastreia-se, em duas etapas, sendo a primeira um breve levantamento bibliográfico e histórico capaz de contextualizar a temática abordada. Num segundo momento, passa-se à Análise Crítica do discurso dos textos selecionados, que abordem crimes sexuais, em especial àqueles em que há de alguma forma a culpabilização da vítima. Busca-se, com isso, as possíveis relações entre a narrativa jornalística e a culpabilização da vítima, para ao final analisar os resultados encontrados.

\section{A construção do cenário social de desigualdade de gênero}

O tema sob investigação é um problema atual, fruto da desigualdade existente entre os gêneros. Admitimos, para os propósitos deste trabalho, as premissas de Frederici (2017, p.13), segundo a qual esta desigualdade decorre de uma cultura que se consolidou coma apropriação do corpo das mulheres pelo capitalismo.

Essa cultura estabelece papeis diferentes para homens e mulheres, cabendo à mulher o espaço privado de mais valia, o recato, a submissão, a criação dos filhos e ao homem o espaço público, o trabalho e o domínio sobre a mulher (VALENÇA, 2007).

Esse era, aliás, o pensamento de Rousseau:

A rispidez dos deveres relativos dos dois sexos não é e nem pode ser o mesmo. Quando a mulher se queixa a respeito da injusta desigualdade que o homem impõe, não tem razão, essa desigualdade não é uma instituição humana ou, pelo menos, obra do preconceito, e sim da razão, 


\section{VOZES $_{\text {\&IÁLORO }}^{\mid}$}

Itajaí, v. 18, n. 02, jul/dez 2019

cabe a quem a natureza encarregou o cuidado com os filhos a responsabilidade disso peranteoutros.(ROUSSEAU APUD DANTAS, p.03, 2017)

Essas repetições prevalecem por meio das regras impostas às mulheres pelo capital, criaram-se os códigos sociais, estabelecendo-se, desde então, padrões de condutas a serem seguidos por ambos os gênero se reproduzidos nas gerações seguintes como o correto, no qual se reproduziram as desigualdades de gênero, o patriarcado, o machismo e o sexismo, que reproduz seus resultados nos dias atuais (FEDERICI, 2017, p. 416-418).

Na obra intitulada “o poder do macho”, a socióloga e advogada Saffioti (1987, p.18) defende que cumpre ao homem "segundo a ideologia dominante, a função de caçador. Deve perseguir o objeto de seu desejo, da mesma forma que o caçador persegue o animal que deseja matar. Para o poderoso macho importa, em primeiro lugar, seu próprio desejo. Essa visão demonstra como os homens podem extravazar seus desejos sexuais de dominação sobre o corpo da mulher,a tal ponto que culmina na figura do estupro e da desigualdade.

A violência de gênero, fenômeno antigo no Brasil, adquire aspectos multifacetados ao longo do tempo e elucida as relações entre brutalidade e gênero de maneiras pouco óbvias. A análise de Rachel Soihet (2004) é exemplar, neste sentido, ao mostrar como o Rio de Janeiro, no começo do século XX, entrecruzou a violência estatal à necessidade de adequar as mulheres de classes subalternizadas aos padrões de gênero burgueses que garantiam a reprodução do capital sob o regime de invisibilidade do trabalho doméstico.

O Código Penal, o complexo judiciário e a ação policial eram os recursos utilizados pelo sistema vigente a fim de disciplinar, controlar e estabelecer normas para as mulheres dos segmentos populares. Nesse sentido, tal ação procurava se fazer sentir na moderação da linguagem dessas mulheres, estimulando seus "hábitos sadios e as boas maneiras", reprimindo seus excessos verbais. A violência seria presença marcante nesse processo (SOIHET, 2004, p. 305)

A intersecção entre marcadores como classe, raça, gênero e suas relações com processos de violência e sujeição - tenham elas partido do Estado ou do âmbito doméstico - adquiriram aspectos complexos e diferenciados ao longo do tempo, mas é fato que, ao fim do século XX, novas demandas estava colocadas de maneira clara.

Ao analisar a luta e inserção de mulheres trabalhadoras em processos de representação trabalhista, Paola Cappellin Giulani (2004) conclui que:

(...) pelo que se refere à cidadania, sabemos que ainda hoje continua sendo difícil falar de mulheres em um sentido geral no Brasil. De fato, são muito fortes as diferenças e as disparidade entre as mulheres quanto à disponibilidade de recursos econômicos e culturais e, portanto, são díspares as oportunidades e diferentes as trajetórias. Por isso optamos 


\section{VOZES $_{\text {\&DÁLORO }}^{\mid}$}

Itajaí, v. 18, n. 02, jul/dez 2019

pela análise das mulheres trabalhadoras, concentrando-nos na cidadania social - aquela que se refere aos direitos no mundo do trabalho -, diferente da cidadania política - aquela que radica na autodeterminação, na participação e na livre escolha dos representantes políticos -, já que as mulheres têm conquistado esta última desde 1932.Interessa-nos enfatizar a definição de cidadania decorrente da participação das mulheres no mundo do trabalho, na medida em que este envolve os direitos sociais no emprego, enquanto esfera pública, e nas relações familiares, enquanto esfera privada. A demanda de cidadania social, nesse contexto, refere-se às mudanças que promovem a igualdade entre as trabalhadoras e os trabalhadores, quanto ao acesso ao mercado de trabalho, às carreiras, ao sistema de previdência social e aos serviços de assistência. Também se refere à introdução de modelos capazes de valorizar a "igualdade entre homem e mulher", através da partilha das responsabilidades, dos processos de decisões na convivência familiar e também na execução de diferentes atividades. (GIULANI, 2004, p. 555)

\section{A desigualdade de gênero e a estereotipação}

A presença ativa dessa desigualdade cultural, citada anteriormente, fez desencadear o que a psicologia entitula de estereotipação. Locke (2013) já defendia que o ser humano nasce sem nenhum conhecimento, mas o adquire da sociedade e de suas experiências. Pereira (2002) afirma que a estereotipação não é uma ideia inata, pois, é instaurada mediantes fatores como a cultura e os costumes de determinado grupo que ganham vida através do indivíduo, transformando-se em cognições e estímulos que são automaticamente acessadas por pensamentos.

Trindade corrobora:

Depois de percepcionarmos um indivíduo, formamos uma impressão que irá ser categorizada, ou seja, vamos associar as características do indivíduo percepcionando a características de grupos sociais, que achamos semelhantes, agrupando-as numa só ideia simplificada que nos permitirá conhecê-lo e saber o que dele podemos esperar (TRINDADE, 2018, p. 4).

É por essas razões científicas que, segundo o mesmo autor, ao nos depararmos com uma mulher cujas característicascorrespondem aos padrões estabelecidos socialmente, iremos associá-la a ao papeltradicionalmente designado à mulher, ou seja, à representação feminina estabelecida pelo modelo dominante. Esta seria uma estereotipação, por parte do

\footnotetext{
${ }^{5}$ Trindade (2018, p.04) esclarece que a terminologia "stereo"+ "typos" que significa "molde sólido", ou seja, "ideias fixas e duradouras, pois se apresenta-se como verdades indiscutíveis (...) realidades feitas por esquemas mentais que distorcem e generalizam características que podem ser negativas ou positivas". Daí a concepção pejorativa de que existe mulher para os homens "pegarem", quanto para os homens para se casarem.
} 


\section{VOZES $_{\text {\&IÁLORO }}^{\mid}$}

Itajaí, v. 18, n. 02, jul/dez 2019

observador, o qual esperará dessa mulher coisas boas e um bom comportamento em sociedade.

Todavia, quando nosdeparamos com a situação oposta às características demandadas, associamo-na ao grupo oposto, consequentemente dela esperaremos maus comportamentos - um verdadeiro estigma.

O homem não consegue controlar seus extintos sexuais, então, as mulheres, que os provocam, é que deveriam saber se comportar, e não os estupradores. A violência parece surgir aqui como uma correção. A mulher merece e deve ser estuprada para aprender a se comportar. $\mathrm{O}$ acesso dos homens aos corpos das mulheres é livre se elas não impuserem barreiras, como se comportar e se vestir adequadamente (PORTO apud DANTAS, 2017, p.12).

A estereotipação é um processo recíproco. Enquanto "eu" analiso o outro, o outro também me analisa (PEREIRA, 2002). Em sua tese sobre psicologia social defendida na Faculdade de Psicologia de Lisboa, Margarida Meira (2011, p.01) destaca a importância do estudo de estereótipos "que possibilita compreender como se estrutura a informação sobre o mundosocial”.

Não obstante, Meira (2011) reuniu teses de outros autores que, após realizar uma pesquisa de campo, para analisar o funcionamento de estereótipo na mente humana, chegou ao seguinte resultado: possui ativação própria, ou seja, estereotipar alguém é algo automático e inescapável, "eles ocorrem apesar de tentativas de os ultrapassar ou ignorar" (DEVINE apud MEIRA, 2011, p.05), pois "a mente humana precisa pensar com ajuda de categorias (...) sendo impossível evitar este processo” Meira (2011,p.05).

Ainda, Pereira (2002) esclarece que estereotipação negativa de um grupo em relação ao outro, serve como bússola a guiar os sentimentos, julgamentos e sentimentos desse mesmo grupo para com o outro. E é nesse momento que surgem o preconceito e a discriminação.

Sendo o preconceito um sentimento negativo formado antecipadamente sem analisar os fatos, enquanto a discriminação é comportamental, é expressa no modo de agir, na dominação como nos atos de violência, em especial na violência de gênero que é a violência perpetrada contra a mulher em virtude do fato de ser mulher, ou seja, de gênero (TRINDADE, 2018).

A violência contra a mulher é a manifestação das relações de poder historicamente desiguais entre homens e mulheres, que têm perpetuado a dominação pelo homem e a discriminação contra a mulher. Deriva de estruturas culturais que conferem à mulher a condição de inferioridade na família, no trabalho, na comunidade e na sociedade. (TAQUETTE, 2007, p.70). 


\section{VOZES $_{\text {\&DÁLOGO }}^{\mid}$}

Itajaí, v. 18, n. 02, jul/dez 2019

Essas condições mencionadas de estereotipação, desigualdades, preconceitos e discriminações subsidiaram a violência de gênero que hoje é parte de nossa sociedade e são as responsáveis pela culpabilização da mulher, perante a sociedade, quando vítima de crimes (SOUZA,2005).

\section{Jornalismo e as narrativas de estupro}

O exercício e a reflexão sobre o jornalismo comportam a necessidade de pensar tal prática por um enquadramento que valorize sua capacidade de construir a realidade. A partir da teoria do Newsmaking, encontra-se um caminho teórico capaz de viabilizar tais intenções. Ao comentar a obra de Hohlfeldt, Rios e Silva (2008) afirmam que:

(...) o newsmaking é um estudo ligado à sociologia das profissões, no caso o jornalismo que dá ênfase à produção de informações e estuda o profissional jornalista e suas interpretações da notícia, ou seja, a capacidade de participar do acontecimento em suas diferentes etapas, desde a captação de informações até a forma com que ele vai chegar ao receptor. (RIOS; SILVA, 2008, p. 4)

No que se refere especificamente sobre o estupro, Porter e Tomasselli citados por Cardoso (2014, p.72) explicam que essa violência de gênero "é uma forma de reafirmação da ideologia social de dominação masculina. Ao dominar a mulher física e sexualmente, o agressor expressa seu poder e submete sua vítima, portanto, a uma posição inferior”.

A intersecção entre estes conceitos nos leva à necessidade de pensar os processos narrativos sobre o estupro na mídia brasileira. Segundo Nolasco (2006):

É notório o comportamento da mídia em sua linguagem. Até 1980, as mulheres eram culpadas pelos homicídios praticados contra elas. Em 1990, a mídia modificou a sua linguagem referente aos casos, demonstrando mais imparcialidade. Cabe destacar que a evolução da linguagem da mídia acompanha o desenvolvimento da sociedade, referente a leis, lutas de movimentos feministas e formas de pensamento de uma dada sociedade. (NOLASCO, 2001, p. 26)

Apesar dos avanços constatados na produção jornalística, este artigo parte do pressuposto de que resta, ainda, como prática narrativa, espaço para notícias que culpabilizam as vítimas.

Propomos que existem certos paralelos entre os ritmos narrativos da queixa, da maneira como a apresenta Gregori (2006), e as narrativas jornalísticas sobre estupro que

\footnotetext{
${ }^{6}$ Em sintese, o estupro é uma violência de gênero, pois é uma violência praticada pelo sexo masculino sobre o feminino em virtude de sua condição. Enquanto gênero é uma categoria social, que envolve papeis sociais atribuído a homens e mulheres (Scott, 1940, p. 75)
} 


\section{VOZES $_{\text {\&DÁLORO }}^{\mid}$}

Itajaí, v. 18, n. 02, jul/dez 2019

culpabilizam vítimas. Ainda que, evidentemente, não se superponham, há importantes coincidências, como uma estrutura dualista que opõe vítima e agressor de maneira a obscurecer a complexidade das situações em que a violência de gênero ocorre.

Textos jornalísticos desta natureza promovem a desmoralização da mulher, que é vista, inclusive no decorrer da notícia, como a causadora do próprio ato violento sofrido através do seu comportamento, sendo, consequentemente, culpabilizada (CARDOSO, 2014).

Essa culpabilização leva ao desempoderamento da vítima, pois o ônus da culpabilidade do agressor é transferido para mesma, o que pode provocar ataques injustos, tendo como consequências uma desfiliação social, além de implicar a omissão de novas vítimas e gerar a impunidade do agressor. Neste contexto, ao noticiar a violência de gênero culpabilizando a mulher, há um favorecimento da cultura do estupro, o que a amplia a desigualdade e discriminação, violando assim, os Direitos Humanos das Mulheres.

\section{Punir a vítima é o método?}

Assim o pensamento de que a mulher foi estuprada por não se moldar aos padrões sociais que lhe reserva o espaço privado, ao invadir o espaço público masculino para comportar como uma devassa é pedir para que crimes como esse ocorram. Portanto, a partir desses pensamentos "o consentimento da vítima não seria a vontade, mas a sua conduta social. E o crime de estupro uma forma de punir uma conduta incoerente ou uma mulher que não se dá o devido respeito" (VALENÇA, 2017, p.13).

A culpabilização ${ }^{7}$ da mulher vítima de estupro vem ganhando espaço nos estudos acadêmicos e contornos científicos. Sobre essa questão, a vitimologia, ciência que estuda a vítima e a sua participação no crime, defende:

A perigosidade vitimal é um estado psíquico e comportamental em que a vítima se coloca estimulando a sua vitimização. vg. a mulher que usa roupas provocantes, estimulando a libido do estuprador no crime de estupro (RIBEIRO, 2001, p.03).

Há, ainda, um pensamento patriarcal dominante no estudo da vítima asseveram Maia (2003), Dias (2011), Diniz (2017), legalizados pelo artigo 59 do nosso Código Penal o qual diz que o juiz deve avaliar, entre outros fatores, o comportamento da vítima no crime, afinal, "o direito absorve o que a sociedade impõe como certo”. (VALENÇA, 2017, p.19). E o certo para o atual pensamento social dominante é avaliar o

\footnotetext{
7 termo empregado por Willian Ryan pela primeira vez em 1971 para se referir a negros dos EUA, vítimas de preconceito racial e depois emprestado para a crimes sexuais contra mulheres (CARDOSO, 2014 p. 70).
} 


\section{VOZES $_{\text {\&IÁLORO }}^{\mid}$}

Itajaí, v. 18, n. 02, jul/dez 2019

comportamento da mulher.

Nos jornais online de maior repercussão no país, o reflexo do patriarcado não é diferente, pois, não raramente, o crime de estupro ainda é visto como algo que a vítima causou. Ao noticiar o ocorrido,os jornalistas geralmente destacam o comportamento, as vestes da mulher, entre outros fatores:

A conduta pode ou não ensejar no crime de estupro, uma mulher meticulosa, que não se move no oposto das regras impostas pela sociedade, a impossibilita de ser vítima de estupro. A averiguação acaba sendo transferida para a conduta da vítima” (VALENÇA, 2017, p.14).

Isto acaba, através do discurso ultilizado, por reforçar as desiguldades de gênero, contribuindo para a construção de uma visão de grupo inferiorizado, que naturaliza a cultura patriarcal, em que a mulher é propriedade do homem, e esse tem o direito de dispor do seu corpo, da sua vida como bem entender.

\section{O discurso crítico para manutenção da estrutura social}

Chouliaraki e Fairclough(1999, P. 16) alegam a partir da análise crítica do discurso (ADC)que a vida social é um sistema aberto o qual se intercala com as diversas dimensões da vida em eventos queatuarão em conjuntos, sem contudo se fundir em um só.

Assim, ainda segundo os citados autores,na ADC aponta-se que o conceito de práticas sociais $^{8}$ se assenta hierarquicamente entre a representação dos aspectos internalizados de uma sociedade, as estruturas sociais e os eventos que são justamente a materialização dessas práticas da sociedade.

Nessa senda, essas práticas funcionam como conciliadoras sociais: são subordinadas às estruturas e refletirão essa subordinação nos eventos, contudo ainda podem agir no sentido oposto disso, modificando e negando as estruturas desde os eventos que permitirão tal postura.

Os autores também dizem que os pontos sociais discutidos pela ADC se compõe de momentos discursivos e não essencialmente discursivos. O momento discursivo é uma fundamentação de textos com reflexos linguísticos da vida social que, conjuntamente, com os momentos não essencialmente discursivos,ou seja, os que não envolvem um discurso fundamentado, irão produzir e reproduzir as ideologias que reafirmarão ou que desafiarão as estruturas sociais em vigor.

As estruturas sociais, por seu turno, mantêm as relações de poder e as articulam ao significado de hegemonia. Chouliaraki e Fairclough (1999, p. 24) defendem que essa

8são costumes relacionados a específicos espaços e tempos nos quais os seres humanos colocam recursos com a finalidade de se interagirem 


\section{VOZES $_{\text {\&IÁLORO }}^{\mid}$}

Itajaí, v. 18, n. 02, jul/dez 2019

permissão consistirá na "naturalização de práticas e suas relações sociais, bem como as relações entre práticas, como questões de senso comum”. Consequentemente, a dominação é sustentada pela ideia de "verdade universal” que é indiscutivel ou imutável e também nas ideologias que laboram para o poder hegemônico ou dominate.

Nesta análise, a estrutura aqui abordada é a da hegemonia masculina em contrapartida à feminina, e essa naturalização de dominância do masculino sobre o feminino é uma das diversas armas ideológicas utilizadas para a manutenção da estrutura social.

O papel da mídia para a manutenção das estruturações sociais é inegável, pois com o seu alcance massivo populacional, as fontes de comunicação, como os jornais, são responsáveis por boa parte da formação das opiniões do seu público-alvo.Fairclough (1995, p. 44-45) aduz que as representações contida em textos midiáticos propagam, em geral, as ideologias de forma subliminar, utilizando linguagens do senso comum da sociedade para ganhar visibilidade e lucros o que acabam por manter determinadas práticas da sociedade.

Neste artigo trataremos especificamente de uma fragmento do gênero notícia: os títulos. Analisando os títulos é possível prever o que se esperar do restante do texto: “os títulos estabelecerão uma especíe de ligação catafórica com com o corpo da notícia, provocando a leitura de todo o texto" (GUIMARÃES, 1990, p. 52).

Pressupomos que o título de uma notícia está saturado de informações ideológicas, uma vez que possui a responsabilidade de definir sob qual aspecto a notícia será abordada.

Thompson (1995) sugere os princípios da ideologia e seus procedimentos, além das estratégias implícitas utilizadas. O mesmo também afirma que as convicções são uma forma de controle social; elas estabelecem e perpetua relações de poder, redirecionando a atenção das desigualdades sociais, de uma forma que desmotiva uma vontade de mudança.

Os procedimentos da ideologia são primordialmente cinco, apesar de Thompson afirmar que esses princípios não são absolutos: reificação, unificação, fragmentação legitimação, dissimulação.

Thompson explica que o êxito desses procedimentos é garantido através de técnicas para a elaboração de formas simbólicas, as quais descrevem como "amplo aspecto falas, imagens, ações e textos, produzidos por determinados sujeitos e reconhecidos por esses e outros como significativos construtos” (THOMPSON, 1995, p.79).

No primeiro ponto, menciona o citado autor, há uma ligação entre inclusão e exclusão, que estão conectadas aos interesses e função que um conceito tem em relação ao seu público-alvo. As exclusões podem se dar de duas formas: por backgrounding ou supressão.

No backgroundig, os agentes ativos são colocados em segundo plano, suas ações são implícitas na maioria das vezes, entretanto podem ser recuperados em algum ponto do texto pelo leitor. Já na supressão, o agente ativo é retirado permanentemente do texto, não havendo forma de reaver sua participação. 


\section{VOZES $_{\text {\&IÁLORO }}^{\mid}$}

Itajaí, v. 18, n. 02, jul/dez 2019

Para os fins deste artigo utilizaremos apenas categoria de backgrounding (CARDOSO, 2014, p.73-74). Apresentaremos também na análise adiante as implicações possíveis das classes de autonomização, funcionalização e ativação. Para as classes de funcionalização e autonomização, os textos recorrem à personalização dos atores, representando-os como seres humanos.

A diferença entre essas está em sua determinação e indeterminação. Já na funcionalização, os atores sociais são taxado em conformidade com as atividades exercidas por ele em suas relações sociais, podendo ser função ou profissão dentro de um determinado grupo.

Na autonomização, por sua vez, os atores sociaissão ocultadosde forma genérica ou de forma que possa indeterminar a sua identidade. Enquanto na ativação, "ator social possui uma representação ativa, com dinâmicas e em atividades" (VAN LEEUWEN, 2008, p. 43).

Usando técnicas de construções simbólicas e de representação dos atores sociais anteriormente mencionados, os discursos divulgados pelos títulos abordados neste artigo confirmam ideologicamente a condição atual, contribuindo para manter a organização social patriarcal. Essa preservação pode ser compreendida partindo de uma possível lógica de desmoralização da mulher vítima, responsabilizando-a pela violência sofrida e colocando o ofensor como um agente secundário da agressão, conforme veremos adiante.

\section{Dos títulos selecionados}

As manchetes selecionadas para análise representam as narrativas publicadas na plataforma de jornal online G1 no período de 2016/2019, que apesar do lapsto temporal, as narrativas referentes as vitímas de estupro, seguem o padrão que culpabiliza as mulheres pelo crime sofrido.

A análise realizada por esse estudo focou no provável discursivo massivo utilizado para culpabilizar as vítimas das reportagens, o que endossaria a ideologia de opressão do masculino sobre o feminino, conduta disseminada nas estruturas sociais das variadas sociedades do mundo.

Dos títulos a seguir extraímos a seguinte análise:

1)Homem de 33 anos é suspeito de estuprar mulher em Araripina, PEA vítima foi ameaçada com uma faca. Suspeito convidou mulher para ir até a casa dele, onde cometeu o crime. ${ }^{9}$

9Título extraído do G1: 14/04/2016às 07h43: http://g1.globo.com/pe/petrolinaregiao/noticia/2016/04/homem-de-33-anos-e-suspeito-de-estuprar-mulher-em-araripina-pe.html 


\section{VOZES $_{\text {\&IÁLORO }}^{\mid}$}

Itajaí, v. 18, n. 02, jul/dez 2019

O título deixa uma ambiguidade para leitor, primeiro o homem é apenas suspeito, segundo a mulher foi ameaçada com uma faca, e terceiro a mulher foi convidada para ir ao encontro. Ou seja, a fala sobre a mulher denota que ela aceitou o convite para o "suposto" crime.Para Fairclough (2003) e Cardoso (2014), a causalidade das ações do título (representadas pelos verbos convidou e cometeu) ligadas por um pronome relativo "onde" solidifica a ideia de que o estupro foi uma consequência direta, pois, a mulher foi até a casa do suspeito por livre e espontanea vontade.

Isso, aduz Thompson (1995), legitima a violência pela racionalização ao passar a ideia de que foi a imprudência da mulher que causou e, logo, justificou o estupro sofrido, fato que teria sido evitado se ela não tivesse aceitado o convite.

Portanto, o título tem a capacidade de induzir o seu leitor ao erro e a um préjulgamento em relação à vítima, visto que ela já é culpabilizada por suas condutas antes mesmo do desfecho da matéria e dela ter espaço suficiente para que a sua história seja mostrada de forma imparcial.

2) Mulher denuncia homem que conheceu pela internet por roubo e estupro, no AM / Vítima contou não lembrar do abuso sexual por ter ficado inconsciente após ser agredida pelo homem. Caso ocorreu na Zona Norte de Manaus. ${ }^{10}$

O título em análise se refere expressamente a uma suposta imprudência da mulher, vez que o crime ocorreu após um encontro marcado pela internet. Essa expressões, apesar de parecerem inofensivas, não são puramente informativas, pois possuem um tipo de dissimulação ocasionada por deslocamento que ocorre ao transferir características negativas ou positivas de uma coisa ou pessoa para outra.

Nesse caso, a vítima tem, na notícia, uma atenção negativa socialmente condenável, pois não convém a uma mulher marcar um encontro com alguém que acabou de conhecer pela internet. Neste contexto, a informação contida no título em análise faz com que haja um julgamento prévio do leitor, pelas informações exploradas pela mídia. Alguns jornais são tendensios apenas em vender notícias, sem análise critíca da fonte, fazendo que o objeto em questão "a atitude relacionada a mulher" seja avaliada de maneira mesquinha.

3) Polícia investiga denúncia de agressão e estupro a jovem de Rio Preto. Segundo o boletim de ocorrência, vítima discutia com o namorado quando foi agredida com socos e desmaiou. Suspeito não foi localizado pela polícia. ${ }^{11}$

10Título extraído do G1: 22/04/2017 às 16h11:https:/g1.globo.com/am/amazonas/noticia/mulherdenuncia-homem-que-conheceu-pela-internet-por-roubo-e-estupro-no-am.ghtml 11 Título extraído do G1: 06/04/2018 às 16h48:https://g1.globo.com/sp/sao-jose-do-rio-pretoaracatuba/noticia/policia-investiga-denuncia-de-agressao-e-estupro-a-jovem-de-rio-preto.ghtml 


\section{VOZES $_{\text {\&IÁLORO }}^{\mid}$}

Itajaí, v. 18, n. 02, jul/dez 2019

Nesta análise, há também uma causalidade entre as orações (Cardoso, 2014, p.78), pois a forma como o título foi articulado existe, segundo Fairclough (2003), uma implicação lógica que pode ser inferida a partir da linguagem utilizada. No título, infere-se em virtude da mulher relatar a discussão com o namorado, como se fosse um artificio da vítima para vingar o namorado, ou seja, conferindo à vítima o poder de escolha sobre a violência de gênero.

Outro fator que garante a legitimação das palavras do título é que foi dito por uma autoridade, ou seja, pela "polícia” que é a fonte da informação. O léxico escolhido é uma forma de representação discursiva do mundo especificadamente em um ângulo (FAIRCLOUGH, 2003). Por isso, ao mencionar que é um relato policial, o jornal apresenta a versão oficial, a qual pode ser interpretada como irrefutável por seus leitores. Assim, Van Leeuwen (2008) entende que a representação da polícia como um todo, ou seja, como uma corporacâa policial que atesta a veracidade do ocorrido como uma testemunha e não como uma mera fonte individual gerará uma autonomização ao criar um sentido de consenso e, por consequência, o empoderamento da informação.

Para VanLeeuwen (2008) isso é um processo não-aleatório de funcionalização já que chama a atenção do leitor para a conduta da vítima. Utilizar determinados termos na matéria é uma escolha consciente do redator. Richardson (2007) preleciona que jornalistas precisam atribuir um nome para as pessoas citadas na notícia, contudo, ao escolher certo nome ao invés de outro, o autor da notícia empregará uma determinada visão sobre aquilo que se escreve.

4)Mulher diz que foi vítima de estupro por conhecido em Uberaba. Crime teria ocorrido na madrugada deste sábado (19); ela conta que foi até a casa do suspeito para receber doação de latinhas recicláveis. Homem não foi encontrado ${ }^{12}$.

Inicialmente no título há uma variação do verbo "dizer" no qual segundo Halliday e Mathiessen (2004) cria uma forma de relação simbólica na linguagem a partir de uma ideia que projetará o restante da conduta material "ter sido estuprada". Por isso a escolha desse modo verbal ao invés de outros como "afirma ou atesta” (CARDOSO, 2014, p. 75), os quais dariam uma credibilidade semântica maior à fala da vítima, criando dúvidas em relação a sua declaração da mulher.

O título em análise apresenta expressamente uma suposta imprudência da mulher, vez que o crime ocorreu após a mulher ter ido a casa do agressor para receber doações de latinhas recicláveis. Essas expressões, apesar de parecerem inofensivas, não são puramente

12Título extraído do G1: 19/10/2019 às 12h56: https://g1.globo.com/mg/triangulomineiro/noticia/2019/10/19/mulher-diz-que-foi-vitima-de-estupro-por-conhecido-emuberaba.ghtml 


\section{VOZES $_{\text {\&IÁLORO }}^{\mid}$}

Itajaí, v. 18, n. 02, jul/dez 2019

informativas, pois possuem um tipo de dissimulação ocasionada por deslocamento que ocorre ao transferir características negativas ou positivas de uma coisa ou pessoa para outra.

Nesse caso, a vítima passa a ter, na estrutura da notícia, uma atenção negativa já que é socialmente condenável que uma mulher vá a casa de um de homem sozinha, ou seja, como se ela almejasse outra intenção (ter algum tipo de relaçao sexual) ao procurar um homem em sua residência, e o fato ter ocorrido no decorrer da madrugada. O título deixa implícito que a fala da vítima remete a dúvidas quanto a suas verdadeiras intenções, como se ela, ao procurar um homem sozinha, pedisse para ser estuprada.

\section{Conclusão}

A culpabilização da vítima de estupro pelos webjornais não é apenas um problema individual da mulher, mas se converge em um problema cognitivo, complexo e de todos: do agressor, do Estado, das leis, da segurança pública, dos direitos humanos, da mídia, e da própriasociedade.

As quatro manchetes extraídas do portal G1 estudados como amostras, apesar do lapso temporal, ainda permanecem com um padrão muito comum nas notícias veiculadas backgroundig: o foco da estrutura concentra-se na vítima, em voz passiva, e dificilmente no agressor, o que leva a ideia de culpabilização da mulher nos contextos sobre violência.

Assim, para uma análise primária de um tema complexo como o escolhido, revelase uma estratégia adequada a fragmentação em tópicos para estudar a origem da desigualdade de gênero abordada por Federici (2017), Giulani (2004) e Soihet (2004), que procuram demonstrar como o capital e as estruturas de poder internas e internacionais a produzem e reproduzem.

Cria-se, assim, uma reflexão mais rica, mais aprofundada de como o jornalismo absorve e reproduz a violência e a desigualdade de gênero, uma vez que atua como instrumentalização de reafirmação patriarcal. Por isso, a culpabilização da mulher em crimes sexuais é uma prática comum na sociedade.

Em síntese, este artigo é uma análise primária e, por isso, há muito a ser desenvolvido e pesquisado. Os títulos demonstram a persistência de práticas narrativas que culpabilizam as mulheres vítimas de estupro, a despeito dos progressos alcançados na sociedade e nas mídias.

De forma primária,as conclusões apontam no sentido de um discurso midiático capaz de promover a culpabilização da mulher vítima de estupro, a esterotipação, estigmas, violência de gênero e a reafirmação do patriarcado.

Por fim, este trabalho poderá servir de inspiração para outras pesquisas sobre os elementos constitutivos da linguagem jornalística e do fazer jornalismo - tais como o lead, as fontes de informação, as suítes, dentre outros - e seus reflexos na compreensão das violências de gênero sofridas pelas mulheres. Entendemos que identificar como opera a 


\section{VOZES $_{\text {\&DÁLORO }}^{\mid}$}

Itajaí, v. 18, n. 02, jul/dez 2019

linguagem e a técnica jornalística nessas narrativas é um dos caminhos para se encontrar o antídoto a esse modus operandi.

\section{Referências}

APFELBAUM, Erika. Dominação. In: HIRATA, Helena; LABORIE, Françoise; LE DOARÉ, Hélène; SENOTIER, Danièle (Org.). Dicionário Crítico do Feminismo. São Paulo: Editora UNESP, 2009;

BRASIL. Constituição da República Federativa do Brasil (1988). Disponível em:〈http://www.planalto.gov.br/ccivil_03/constituicao/constitui\%C3\%A7ao.htm.>.

Acesso: 18 agot. 2019.

BHASKAR, Roy. Scientific realism and human emancipation. London: Verso, 1986;

CARDOSO, Isabela et al. A mídia na culpabilização da vítima de violência sexual: o discursos de notícias sobre estupro em jornais eletrônicos. EID\&A - Revista Eletrônica de Estudos Integrados em Discurso e Argumentação. Ilheús, no7, p.69-85, dez.2014.

Disponível em: <http://uesc.br/revistas/eidea/revistas/revista7/eid\&a_n7_05_iv.pdf> Acesso: 10jan.2019.

CHOUliARAKI, Lilie; FAIRCLOUGH, Norman. Discourse in Late Modernity. Edinburgh: Edinburgh University Press, 1940;

DANTAS, Fernanda B.C. et al. Violência sexual contra a mulher: culpabilização da vítima. Revista online Fadivale, Governador Valadares. Ano XII, n¹4, 2017. Disponível em:<http://www.fadivale.com.br/portal/revista-online/revistas/2017/Fernanda-BethaniaCardoso- Dantas.pdf $>$

Acesso:07 jan. 2019.

DIAS, Irina M.R. et al. Vitimologia nos crimes sexuais. Rio de Janeiro: ESMEGRJ, 2011.

DINIZ. Eduardo S. et al. O lugar da vítima nas ciências criminais. São Paulo:LiberArs, 2017.

FAIRCLOUGH, Norman. Media discourse. London: Arnold, 1995.

FAIRCLOUGH, Norman.Analysing discourse:Textual analysis for social research. Nova York: Routledge, 2003.

FEDERICI, Silvia. Calibã e a bruxa. Mulheres, corpo e acumulação primitiva. Trad. Coletivo Sycorax. São Paulo: Elefante, 2017.

FUCCIA, Eduardo Veloso. Reportagem policial: um jornalismo peculiar. São Paulo: Realejo, 2008. 


\section{VOZES $_{\text {\&IÁLORO }}^{\mid}$}

Itajaí, v. 18, n. 02, jul/dez 2019

GIULANI, Paola Cappellin. Os movimentos de trabalhadoras e a sociedade brasileira. In: Del Priore, Mary. História das Mulheres no Brasil. São Paulo: Contexto, 2004.

GRAMSCI, Antonio. A Gramsci reader: selected writings 1916-1935. David Forgacs (Org.). Londres: Lawrence and Wishart, 1988.

GREGORI, Maria Filomena.Cenas e queixas: mulheres e relações violentas. Novos Estudos. CEBRAP, São Paulo, v. 23, p. 163-175, 1989.

G1, portal: Homem de 33 anos é suspeito de estuprar mulher em Araripina, PE http://g1.globo.com/pe/petrolina-regiao/noticia/2016/04/homem-de-33-anos-e-suspeitode-estuprar-mulher-em-araripina-pe.htmlAcesso 22 out. 2019.

G1, portal: Mulher denuncia homem que conheceu pela internet por roubo e estupro, no AM: https://g1.globo.com/am/amazonas/noticia/mulher-denuncia-homem-que-conheceupela-internet-por-roubo-e-estupro-no-am.ghtmlAcesso 22 out. 2019.

G1, portal:Polícia investiga denúncia de agressão e estupro a jovem de Rio Preto:https://g1.globo.com/sp/sao-jose-do-rio-preto-aracatuba/noticia/policia-investigadenuncia-de-agressao-e-estupro-a-jovem-de-rio-preto.ghtmlAcesso 22 out. 2019.

G1, portal:Mulher diz que foi vítima de estupro por conhecido em Uberaba: https://g1.globo.com/mg/triangulo-mineiro/noticia/2019/10/19/mulher-diz-que-foi-vitimade-estupro-por-conhecido-em-uberaba.ghtmlAcesso 22 out. 2019.

LOCKE, John. Ensaio acerca do entendimentohumano. São Paulo: Saraiva, 2013.

MAIA,Luciano Mariz. Vitimologia e direitoshumanos. Disponível em:〈http://www.dhnet.org.br/direitos/militantes/lucianomaia/lmmaia_vitimologia_dh.pdf> Acesso 08 out. 2019.

MEIRA, Margarida: Acção do contexto nos estereótipos: influência e limites. Tese de Mestrado em psicologia. Universidade de Lisboa, 2010/2011. Disponível em:<http://repositorio.ul.pt/bitstream/10451/4959/1/ulfpie039657_tm.pdf>Acesso: 10 set.2019.

MORENO, R. A mulher na mídia: controle social comparado. São Paulo: Publisher,2013.

NASCIMENTO, Patrícia Ceolin do et al. Técnicas de redação em jornalismo: o texto da notícia. São Paulo: Saraiva, 2012.

NOLASCO, Cláudia de Abreu Pereira. Violência contra a mulher e mídia: Um estudo sobre a influência da mídia nas violências cometidas as mulheres do município de Macaé/RJ. 2011, 77 f. Trabalho de Conclusão de Curso (Curso de Serviço Social) Universidade Federal Fluminense.

OLIVEIRA, Rosiska Darcy de. As mulheres, os direitos humanos e a democracia. Brasília: FDD, 2014. 


\section{VOZES $_{\text {\&DÁLORO }}^{\mid}$}

Itajaí, v. 18, n. 02, jul/dez 2019

PEREIRA, E. M. Psicologia social dos estereótipos. São Paulo: EPU, 2002.

RIBEIRO, Lúcio R. P. Vitimologia. Revista de Direito Penal, nº7, abr-maio/2001. Doutrina 3137.

Disponível:<http://www.mpsp.mp.br/portal/page/portal/documentacao_e_divulgacao /doc_biblioteca/bibli_servicos_produtos/bibli_boletim/bibli_bol_2006/RDP_07_30.pdf> Aces so: 05 set. 2019.

RIOS, Patrícia; SILVA, Elane Gomes. A teoria do Newsmakinge a influência da Internet no cotidiano dos jornalistas: estudo de caso das editorias de Cultura da Paraíba. In: Intercom - Sociedade Brasileira de Estudos Interdisciplinares da Comunicação, 23, 2008, Natal, p.1-12.

RODRIGUES, Aroldo et al. Psicologia social. 27ed. São Paulo: Vozes, 2008.

ROSSI, Giovana. A culpabilização da vítima no crime de estupro: estereótipos de gênero e o mito da imparcialidade jurídica. São Paulo: Empório, 2014.

SAFFIOTI, Hellieth I. B. O poder do macho. São Paulo: Moderna, 1987.

SOIHET, Rachel. Mulheres pobres e violência no Brasil urbano. In: Del Priore, Mary. História das Mulheres no Brasil. São Paulo: Contexto, 2004.

SCOTT, Joan. Gênero: uma categoria útil de análise histórica.Educação e realidade. São Paulo, 1990 .

SILVA, Luciana Santos. Estudo de caso de estupro coletivo: por que a vítima é culpabilizada?.Disponível:<http://canalcienciascriminais.jusbrasil.com.br/artigos/3443859 198/estudo-de-caso-do-estupro-coletivo-por-que-a-vitima-e-culpabilizada-?>Acesso:17 out. 2019 .

SOUZA, Cecília de Mello et al. Violência sexual no Brasil: perspectivas e desafios. Brasília: IPAS, 2005.

SOUZA, José Guilherme de. Vitimologia e violência nos crimes sexuais: uma abordagem interdisciplinar. São Paulo: Fabris, 2013.

SOUZA, Isabela A. O preconceito nosso de cada dia: um discurso sobre as práticas discursivas no cotidiano. Tese de Doutorado em psicologia social. PUC-SP, São Paulo, 2008. Disponível em:〈http://livros01.livrosgratis.com.br/cp058855.pdf〉

Acesso: 12 out. 2019.

STECANELA, Nilda. Mulheres e direitos humanos desfazendo imagens, (re)construindo identidades. Florianópolis: Interthesis, 2009.

TAQUETTE, Stella R. et al. Mulher adolescente/jovem em situação de violência: propostas de intervenção e saúde. Brasília: URRJ, 2007. 


\section{VOZES $_{\text {\&IÁLOGO }}^{\mid}$}

Itajaí, v. 18, n. 02, jul/dez 2019

TRINDADE, Antonio et al. Estereótipos, preconceito e discriminação. São Paulo: IEI, 2017.

VALENÇA, Bianca Pereira. A culpabilização das vítimas no crime de estupro: análise de decisões judiciais. Trabalho de Conclusão de Curso de Direito. Curuaru: ASCESUNITA,2017.

Disponível<:http://repositorio.asces.edu.br/bitstream/123456789/1138/1/Artigo\%20Cient \%C3\%ADfico\%2020A\%20CULPABILIZA\%C3\%87\%C3\%830\%20DAS\%20V\%C3\%8D TIMAS\%20NO\%20CRIME\%20DE\%20ESTUPRO.pdf>acesso 09 set. 2019. 